Article

\title{
Surface Enhanced Raman Spectroscopy of Lactoferrin Adsorbed on Silvered Porous Silicon Covered with Graphene
}

\author{
Sergey Zavatski ${ }^{1}{ }^{\mathbb{D}}$, Nadia Khinevich ${ }^{1}$, Kseniya Girel ${ }^{1}$, Sergey Redko ${ }^{2}{ }^{\mathbb{D}}$, Nikolai Kovalchuk ${ }^{3}$, \\ Ivan Komissarov ${ }^{3}$, Vladimir Lukashevich ${ }^{4}$, Igor Semak ${ }^{5}{ }^{-}$, Kahramon Mamatkulov ${ }^{6}$, \\ Maria Vorobyeva ${ }^{6}$, Grigory Arzumanyan ${ }^{6,7}$ (D) and Hanna Bandarenka ${ }^{1, *(D)}$ \\ 1 Laboratory of Applied Plasmonics, Belarusian State University of Informatics and Radioelectronics, \\ 220013 Minsk, Belarus; sergeyzavatski13@gmail.com (S.Z.); khinevichnadia@gmail.com (N.K.); \\ k.girel@bsuir.by (K.G.) \\ 2 Laboratory of Materials and Structures of Nanoelectronics, Belarusian State University of Informatics and \\ Radioelectronics, 220013 Minsk, Belarus; ml.redkov@gmail.com \\ 3 Laboratory of Integrated Micro- and Nanosystems, Belarusian State University of Informatics and \\ Radioelectronics, 220013 Minsk, Belarus; n.kovalchuk@bsuir.by (N.K.); komissarov@yahoo.com (I.K.) \\ 4 Laboratory of Nutrition and Sports Physiology, Institute of Physiology of the National Academy of Sciences \\ of Belarus, 220072 Minsk, Belarus; lukashvs@rambler.ru \\ 5 Department of Biochemistry, Belarusian State University, 220030 Minsk, Belarus; semak@bsu.by \\ 6 Laboratory of Neutron Physics, Joint Institute for Nuclear Research, 141980 Dubna, Russia; \\ hero170184@mail.ru (K.M.); vmu.chemist@mail.ru (M.V.); arzuman@jinr.ru (G.A.) \\ 7 Dubna State University, 141982 Dubna, Russia \\ * Correspondence: h.bandarenka@bsuir.by; Tel.: +37-517-293-8843
}

Received: 17 December 2018; Accepted: 20 February 2019; Published: 28 February 2019

\begin{abstract}
We registered surface enhanced Raman scattering (SERS) spectra of the human lactoferrin molecules adsorbed on a silvered porous silicon (por-Si) from $10^{-6}-10^{-18} \mathrm{M}$ solutions. It was found that the por-Si template causes a negative surface potential of silver particles and their chemical resistivity to oxidation. These properties provided to attract positively charged lactoferrin molecules and prevent their interaction with metallic particles upon $473 \mathrm{~nm}$ laser excitation. The SERS spectra of lactoferrin adsorbed from $10^{-6} \mathrm{M}$ solution were rather weak but a decrease of the concentration to $10^{-10} \mathrm{M}$ led to an enormous growth of the SERS signal. This effect took place as oligomers of lactoferrin were broken down to monomeric units while its concentration was reduced. Oligomers are too large for a uniform overlap with electromagnetic field from silver particles. They cannot provide an intensive SERS signal from the top part of the molecules in contrast to monomers that can be completely covered by the electromagnetic field. The SERS spectra of lactoferrin at the $10^{-14}$ and $10^{-16} \mathrm{M}$ concentrations were less intensive and started to change due to increasing contribution from the laser burned molecules. To prevent overheating the analyte molecules on the silvered por-Si were protected with graphene, which allowed the detection of lactoferrin adsorbed from the $10^{-18}$ M solution.
\end{abstract}

Keywords: surface enhanced Raman scattering; silver; porous silicon; graphene; lactoferrin; attomolar concentration

\section{Introduction}

The development of biosensing techniques to overcome the problem of reliable detection, identification, and structural study of diverse bioorganic molecules at ultralow concentrations is still an urgent objective of specialists in many spheres including medicine, biology, forensics, ecology, 
pharmaceutics and so on. This is proven by the statistics on "biosensing" papers, the number of which has increased greatly in the last years (Figure 1). Recently, there has been a rapid growth of interest in biosensing studies involving a variety of optical systems, devices and methods combined with nanomaterials, which are able to find molecules in physiological liquids and living cells at extremely low concentrations (Figure 1, inset) [1-10]. The main goals of these studies include non-invasive tests, medical diagnostics and therapy of different types of cancer [6,8], brain diseases [9], viruses-induced illnesses [10] and other dangers to human health. Accuracy and reliability are important requirements of desirable biosensing to reduce risks of false results. Raman spectroscopy has been considered an appropriate approach for biosensing [11]. Most chemical compounds have their own unique Raman spectrum signature, which allows identifying the molecule in the same way as one establishes a person's identity by determining fingerprints. The undoubted advantages of Raman spectroscopy over other methods are its non-invasiveness, high resolution, negligible Raman intensity of water-based solvents, short term (a few minutes) analysis, non-complicated sample preparation, single excitation wavelength, etc. On the other hand, this technique has a major drawback that is a low sensitivity, which limits its practical application. The reason for this lack is that only one Raman photon out of $10^{6}-10^{8}$ photons of incident light can be scattered. However, there is an effective way to solve this problem via the placement of analyte molecules on a surface of nanostructures of coinage metals that provides a great enhancement of the Raman signal by several orders of magnitude [12-14]. This effect is known as surface enhanced Raman scattering (SERS). The metallic nanomaterials are accepted to be called SERS-active substrates. The major contribution to the Raman signal enhancement is due to the surface plasmon resonance in metallic nanostructures arising under laser excitation [12-14]. At the same time, charge transfer between molecules of analyte and metallic nanostructures can also cause a signal increase [12-14]. Apart from its outstanding sensitivity, the Raman spectroscopy exploiting the SERS effect has additional benefits, such as the inhibition of luminescence of organic analytes by the metal particles and the selectivity provided by the proper functionalization of the SERS-active substrates. Therefore, the SERS-spectroscopy provides an opportunity of an ultrasensitive biochemical assay including precise identification and study of different molecules.

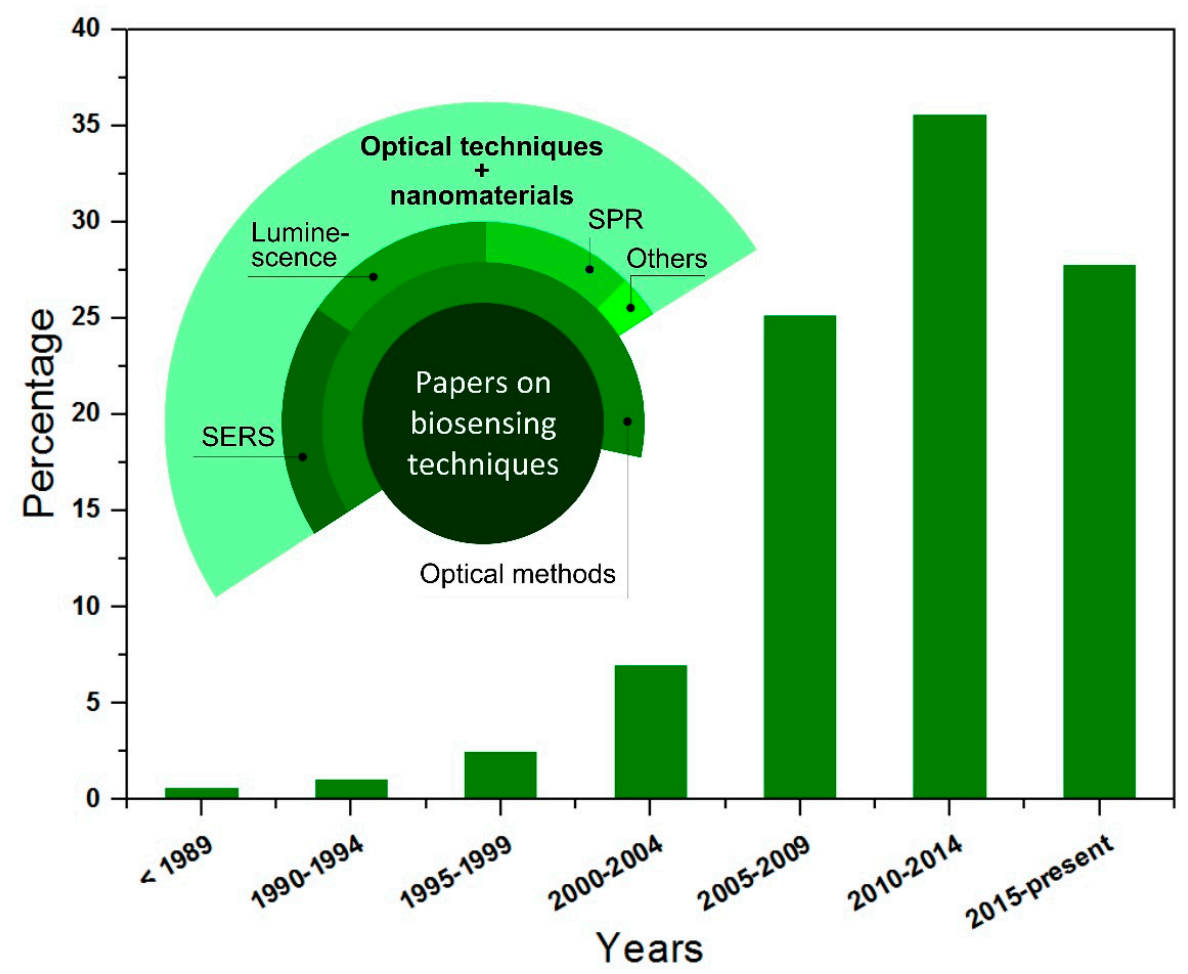

Figure 1. Number of papers on biosensing by year; inset shows the distribution of papers on biosensing based on the technique used (Google Academy, accessed on 30 November 2018). 
A special interest of SERS-spectroscopy has been paid to the detection and study of bioorganic macromolecules, in particular, to proteins that possess antiseptic properties, as they are prospective in the development of nanomaterials for the prevention and therapy of bacteria/virus-induced diseases [15]. Lactoferrin is a bright example of such proteins. It is a non-heme mammalian iron-binding glycoprotein, belonging to the transferrin family [16]. In addition to the iron transport, lactoferrin modulates immune responses, has antioxidant activity and anti-inflammatory properties, and participates in the regulation of cell growth and differentiation [17]. Lactoferrin is present at the highest concentration $(1 \mathrm{mg} / \mathrm{mL})$ in the milk of humans and other mammals [18]. It can also be found in a lower amount in blood plasma, neutrophils, saliva, bile, pancreatic secretion, and tears [19]. For example, the lactoferrin concentration in the tear of a healthy person varies between $10^{-5}$ and $2 \cdot 10^{-5} \mathrm{M}$ depending on the age [20]. When an eye is diseased, the lactoferrin concentration decreases more than the order of magnitude and its precise control in the tear liquid can help to distinguish causes of eye illness [21]. It was also revealed that lactoferrin affects cell growth (at $10^{-8}-10^{-6} \mathrm{M}$ ) and sucrase and lactase mRNA expression $\left(a t 10^{-10} \mathrm{M}\right)$ [22]. It is an urgent challenge to distinguish lactoferrin in a mixture of different proteins, when the SERS technique is used. Some features of the lactoferrin Raman spectra can be found in the literature [23] but they are rather subtle. At the same time, the lactoferrin detection in its water solutions is very important, as they can be used in the therapy of different diseases including cancer. Recently, it was reported that exogenous lactoferrin can affect the rate of tumor cells growth [24]. In addition, it was shown that recombinant human lactoferrin has a beneficial effect on the intestinal microflora, ultrastructure of the liver and intestines, activated lipid metabolism and steroidogenesis [25]. Proper therapy will require the precise control of this protein concentration in its solutions for oral, drip administration, etc. Therefore, monitoring the changes of the amount of this protein at submolar level in liquids is of great interest to research areas related to biomedicine.

It should be noted that nowadays an enzyme-linked immunoassay (ELISA) and a high performance liquid chromatography (HPLC) are widespread techniques for the basic research and clinical investigation of proteins. Conducting the ELISA includes at least one antibody with a specific immune response against the antigen of interest. The ELISA detection methodologies have a high specificity, provide enough reproducibility of data and allow the quantitative investigation of analytes [26]. However, the general shortages of the conventional ELISA are that it is a tedious/laborious procedure, has limited multiplexing options, and operates with relatively large sample volumes. Moreover, the detection limit of the conventional ELISA is near a nanomolar concentration, which is inadequate to reach the clinical threshold of many proteins' biomarkers, especially in the early stage of diseases [27]. For example, Ying Pan and co-authors [28] reached the $0.145 \mathrm{ng} / \mathrm{mL}$ detection limit using the ELISA technique. In Reference [29] the detection limit of the lactoferrin of $2.5 \mathrm{ng} / \mathrm{mL}$ was reported. In addition, the ELISA is known to take $24 \mathrm{~h}$ or even several days to get results. Thus, there is an urgent need to find a faster analysis. Liquid chromatography (LC) is a physical separation technique conducted in the liquid phase. The HPLC approach is a modern form of the LC method that uses small-particle columns, through which the mobile phase is pumped at a high pressure. The HPLC has advantages over other methods because it is capable of the multicomponent analysis of real-life samples and complex mixtures with good resolution and sensitivity. This method has been employed for determining all major whey proteins including lactoferrin. However, the HPLC suffers from several well-known disadvantages. First, there is no universal detector, hence the detection is more problematic if the analyte does not absorb ultraviolet (UV) or cannot be easily ionized for mass spectrometric detection. Second, the HPLC has many operating parameters and is more inconvenient for routine measurements. Third, although the HPLC can often simplify and speed up the solution separation process, the cost of the HPLC equipment can become tremendous. Finally, similar to the ELISA technique, the HPLC hardly provides a suitable detection limit of protein biomarkers for clinical application. For example, Zhang et al. achieved the detection limit of $0.6 \mathrm{mg} / 100 \mathrm{~g}$ for the lactoferrin [30]. Krol et al. showed the $8.7 \mathrm{mg} / \mathrm{L}$ detection 
limit for the lactoferrin standard during calibration of the chromatographic system [31]. Compared with these techniques, the SERS-spectroscopy exhibits a unique blend of advantages, such as very high sensitivity, non-invasive probing, compatibility with water solutions, simplicity of a sample preparation, label-free monitoring for specific analyte in complex mixtures [32], and a small sample volume. Moreover, SERS-spectroscopy does not require specific and expensive equipment, which allows routine measurements to be conducted even by a non-specialist.

Despite SERS-spectroscopy allows one to study molecules at extremely low concentrations, studies devoted to the deep investigation of lactoferrin by this method have not been presented yet. This is probably connected with difficulties that appear during the SERS analysis of organic species of high molecular weight. In general, the enhancement of Raman signals provided by metallic nanostructures depends on the substrate nanotexture, the type of metal, the excitation wavelength, its polarization, the orientation of the bonds, which vibrations we have to detect, the possible anharmonicity of oscillations during adsorption on a substrate, chemical bonds with the substrate, etc. These conditions greatly influence the results of SERS analysis, especially during the study of large molecules such as DNAs, proteins, and even peptides [11,33]. Their conformation is changed on the solid substrate. Some bonds cannot be located in the "hot spots", resulting in a weak reproducibility of the SERS spectra [34]. Difficulties have been also observed at low concentrations, when there is a need of an extremely high enhancement factor to detect substance. They are because of irreversible changes of the analyte molecules due to their interaction with metallic nanostructures and destruction upon the photothermal effect from the laser [35]. What is more, silver nanoparticles, which are very attractive for SERS-spectroscopy as they provide the greatest activity referred to electromagnetic mechanism, show the surface plasmon resonance in a blue range close to UV. The combination of d-metal and UV excitation can also result in organic denaturation. In addition, silver nanostructures are known to be positively charged. This is a benefit if there is a need to penetrate via the cell membrane of harmful species or to interact with protein for a creation of antiseptic nanoparticles [15,36]. However, it turns into a disadvantage for SERS-spectroscopy because silver nanoparticles are easily oxidized under ambient conditions. Thus, they show a losing reproducibility and weakening intensity of the SERS signal in the course of time.

The present work pursued the goal of overcoming the above-mentioned hurdles of the SERS spectroscopy of biomolecules with a high molecular weight that include: (i) The weak reproducibility of the SERS spectra due to partial location of the molecule in the hot spot and (ii) destructive effect from the laser-metal particle interaction. We also aimed at finding the minimal concentration of the test macromolecules in the water solutions, at which an analyte can be detected. The recombinant human lactoferrin was used as test analyte molecules. To achieve these objectives, we proposed to study and use the beneficial cooperative effect from the SERS-active substrates based on a silvered por-Si and the protection of the analyte molecules with graphene. The silvered por-Si has been already successfully utilized as the SERS-active substrate [37-40] demonstrating an exceptional detection limit down to the femtomolar concentration [41-44], a high SERS signal reproducibility [45-47] and a long shelf life of up to two years [47], which is not typical for the silver-based SERS-active substrates. Despite the last feature, which has not been plausibly explained before, we suppose that the silver nanostructures on the por-Si surface have an improved chemical resistance preventing their oxidation and agglomeration. They must be strongly anchored on the negatively charged por-Si surface, which is composed of a huge number of nanocracks and roughness with broken bonds [48]. Therefore, the silver nanostructures on the por-Si are expected to show less affinity to the oxidation and aggressiveness to organic molecules. At the same time, graphene, which is known to enhance the Raman signal itself [49], will contribute to the amplification of the Raman signal being placed on the surface of metal nanostructures [50,51]. What is more, if graphene covers the analyte molecules, it can protect them from the environment and provide a heat sink due to the high thermal conductivity. This will prevent the photo- and thermal-induced destruction of analyte. 


\section{Materials and Methods}

Monocrystalline $\mathrm{n}^{+}$-type $\mathrm{Si}$ wafers $(c-\mathrm{Si})$ were used for the fabrication of the por-Si template. Prior to the por-Si formation, the $\mathrm{Si}$ wafers were cleaned in a solution of $\mathrm{NH}_{4} \mathrm{OH}, \mathrm{H}_{2} \mathrm{O}_{2}$ and $\mathrm{H}_{2} \mathrm{O}$ mixed at a volume ratio of 1:1:4. Native $\mathrm{SiO}_{2}$ was removed from the $\mathrm{Si}$ wafer in diluted $\mathrm{HF}$ (4.5\%). The por-Si layers of a $5 \mu \mathrm{m}$ thickness, a $75 \%$ porosity and a 70-100 nm pore diameter were fabricated by an electrochemical anodization according to the procedure described elsewhere [52]. The electrochemical anodization process was carried out with the potentiostat/galvanostat AUTOLAB PGSTAT302n. After anodization, a silver immersion deposition on the por-Si was performed from a water-ethanol solution of $3 \mathrm{mM} \mathrm{AgNO}$ for $70 \mathrm{~min}$ resulting in a dominant deposition of silver nanoparticles on an external surface of the porous material [53]. Then the samples were rinsed with deionized water and air-dried. The photo of the resulting substrate is shown in Figure S1. The silvered $c$-Si samples were also prepared using the same deposition conditions to compare their surface potential with that of the silvered por-Si.

To measure the surface potential of the silvered $c$-Si and por-Si, a platinum reference electrode was used. The electrode was located near the sample surface. The surface potential measurements of the samples were carried out in deionized water and $10^{-6} \mathrm{M}$ lactoferrin solution.

Chemical vapor deposition (CVD) was used for the synthesis of graphene. Electrochemically polished copper foil was annealed for $1 \mathrm{~h}$ at $1050{ }^{\circ} \mathrm{C}$ in $\mathrm{Ar}$ and $\mathrm{H}_{2}$ gases' flow with a rate of 160 and $150 \mathrm{~cm}^{3} / \mathrm{min}$, respectively. Then a $4 \mathrm{~cm}^{3} /$ min methane flow was introduced into the CVD reactor for $10 \mathrm{~min}$. We used a wet-chemical transfer of graphene without a polymer support. A preparation of the graphene films for the transfer was carried out as follows: (i) The underside of the copper foil was processed for 3 min in a solution of $\mathrm{HNO}_{3}: \mathrm{H}_{2} \mathrm{O}$, mixed in a volume ratio of 1:3 and (ii) the copper foil was completely dissolved in an aqueous solution of $\mathrm{FeCl}_{3}$. As a result, the graphene film remained floating on the surface of the solution. Before the graphene transfer, this solution was carefully replaced several times with distilled water, which facilitated its purification from the products of chemical reactions. This operation was carried out with the aim of minimizing undesirable adsorption of various compounds on the surface of the SERS-active substrate, which could distort the results of subsequent measurements. When working on the transfer process, the substrate both containing the $c$-Si and silvered por-Si areas was immersed in the solution, placed under the graphene film and lifted up from the solution. In this case, the graphene film remained on the surface of the substrate.

A morphology of the experimental samples was studied with the scanning electron microscope (SEM) Hitachi S4800, which provided $1 \mathrm{~nm}$ resolution. The elemental composition of the samples was determined using SEM Cambridge Instruments Stereoscan-360 with a Link Analytical AN 10,000-energy dispersive X-ray (EDX) analyzer. The diameter of the focused electron beam was about $2 \mu \mathrm{m}$. The depth of analysis did not exceed $1 \mu \mathrm{m}$.

The simulations of electric field strength and heat transfer in the silvered por-Si, both free of graphene and covered with it, were performed using COMSOL Multiphysics 5.3a.

Organic dye Rhodamine 6G (R6G) and recombinant human lactoferrin [24,25] were used as analytes for the SERS measurements. The R6G dye (purchased from Sigma-Aldrich) and lactoferrin (received from the Department of Biochemistry of the Belarusian State University) had a 98\% purity. Recombinant human lactoferrin from milk of transgenic goats was purified using cation-exchange chromatography according to the procedure described elsewhere [24,25]. The physicochemical characteristics of the recombinant lactoferrin were similar to those of natural human lactoferrin (from woman's milk) as revealed by mass spectrometry and peptide mapping [24,25]. According to Reference [54], human milk lactoferrin is saturated with iron up to $10 \%$. R6G was chosen to study the influence of graphene on the SERS-activity of the silvered substrates. The analytes' powders were dissolved in a deionized water to obtain the solutions of $10^{-6}-10^{-18} \mathrm{M}$ concentrations. The solutions of lactoferrin were clear and soluble at different concentrations. Good solubility of lactoferrin in water solutions is typical for this protein even while the $\mathrm{pH}$ changes [55]. The $c$-Si and silvered por-Si samples of a $0.25 \mathrm{~cm}^{2}$ surface area were immersed in $1 \mathrm{~mL}$ of the analytes' solutions for $1 \mathrm{~h}$ before 
the measurements and then rinsed in deionized water for $30 \mathrm{~s}$ to remove an excess of the analyte molecules. The lactoferrin retained its solubility during the immersion of the silvered samples in its solutions. The SERS spectra were registered with a 3D scanning confocal microscope Confotec NR500. Laser with a $473 \mathrm{~nm}$ wavelength and a spot diameter about $600 \mathrm{~nm}$ was used to excite the samples. Laser had a $25 \mathrm{~mW}$ power that decreased via optical system and $\times 100$ objective down to $1.45 \mathrm{~mW}$. We used both single point and mapping SERS measurements. They are described in more detail below, in the paragraphs related to the SERS-spectroscopy of different samples. To check the repeatability of the results of the spectroscopic study, we recorded the SERS spectra in two areas of the single substrate, one area of the other substrate from the same batch and one area of the substrate from a different batch for each research stage.

\section{Results and Discussion}

\subsection{Characterization of SERS-Active Substrates}

The fabrication technique of the SERS-active substrates used in this work has been already reported [47]. It is known that particles of the coinage metals (including silver) can be deposited on the por-Si surface because of oxidation of silicon atoms with silver ions from the solution and their following reduction in an atomic form $[38,40,56]$. In contrast to $c-S i$, the por-Si material provides more electrons for reduction and centers for nucleation of the silver atoms due to an extremely developed nanostructured surface. In this work, we used the silvered por-Si substrates that have been well-studied before $[53,57]$. The SERS-active layer of these substrates presents non-continuous film composed of quasi-spherical silver particles of polycrystalline nature, which dominating sizes are in the range of 10-150 nm, however, some of them have diameters of 150-700 nm (see Figure S2). Namely, these structures were found to demonstrate the greatest shelf life [47]. To check the idea of a negative surface charge of the silvered por-Si, which prevents its oxidation, we compared the surface potential of the $c$-Si and por-Si samples in water. It was found to be equal to $+0.01 \mathrm{~V}$ for the silvered surface of the flat silicon and to $-0.3 \mathrm{~V}$ for that of por-Si. Next, we studied the elemental composition of the as-prepared substrates and the substrates air-aged for six months. All the EDX spectra looked rather similar and it was possible to reveal the content of the samples via their quantitative analysis. That is why we presented only one EDX spectrum typical for the silvered Si-based samples on Figure S3. An amount of oxygen in the silvered $c$-Si increased almost twice while the sample based on the por-Si showed a nearly constant amount of oxygen (Table 1). The increase of the oxygen amount cannot be explained by the silicon oxidation in the air. The silver deposition from the water-based solutions leads to the formation of the silicon dioxide layer that protects the underlying $c$-Si substrate from the further oxidation. Therefore, the silver particles deposited on the por-Si are characterized by a better stability due to the resistance to oxidation. It should be considered that the higher oxygen amount in the silvered por-Si (in contrast to that based on $c$-Si) is due to the greater surface area of the porous material for the layer of the $1 \mu \mathrm{m}$ thickness analyzed by the EDX spectrometry. The other beneficial effect is the negative charge of the silver particles provided by the por-Si template. This will very likely prevent interactions with the bioorganic analyte that is typical for positively charged silver particles $[15,50]$. As a result, the SERS-spectra will show objective information on the structure of the studied biomolecules.

Table 1. Results of the EDX analysis.

\begin{tabular}{cccccc}
\hline \multirow{2}{*}{ Element } & \multirow{2}{*}{ Series } & \multicolumn{4}{c}{ At. $\%$} \\
\cline { 3 - 6 } & & Fresh Ag/c-Si & Aged Ag/c-Si & Fresh Ag/por-Si & Aged Ag/por-Si \\
\hline $\mathrm{C}$ & $\mathrm{K}$ & 18.32 & 20.71 & 16.74 & 20.70 \\
$\mathrm{O}$ & $\mathrm{K}$ & 2.03 & 3.92 & 4.25 & 4.30 \\
$\mathrm{Si}$ & $\mathrm{K}$ & 57.46 & 48.08 & 42.46 & 43.20 \\
$\mathrm{Ag}$ & $\mathrm{L}$ & 22.13 & 18.48 & 36.55 & 31.71 \\
\hline
\end{tabular}




\subsection{Characterization of Graphene-Containing Films}

It is known that graphite's Raman spectra can contain three intensive bands- $G, 2 D$, and D [58]. The $\mathrm{G}$ band $\left(1582 \mathrm{~cm}^{-1}\right)$ is associated with a doubly degenerated phonon mode of E2g symmetry from the center of the Brillouin zone. The 2D band (around $2710 \mathrm{~cm}^{-1}$ ) is due to resonant light scattering with the participation of two phonons of the same energy, but with the opposite direction of the pulse, and gives information about the ordering of graphite (graphene) layers. The band $\mathrm{D}\left(1352 \mathrm{~cm}^{-1}\right)$ characterizes defects in the graphite (graphene) structure. To characterize a film formed by the CVD method we first made Rayleigh images of graphene-containing film transferred to the $c$-Si surface and measured its Raman spectra (Figure 2a). Following the Rayleigh images, dark and light spots were observed in the film, which are supposedly caused by irregularity of the graphene-containing coating. The Raman spectra were registered in both spots. The 2D band positions were shifted to the higher frequencies. This shift can be caused by mechanical stress in the film. Paper [59] reports that the number of graphene layers is calculated from a ratio of intensities of $G$ and $2 \mathrm{D}$ bands. $\mathrm{I}_{\mathrm{G}} / \mathrm{I}_{2 \mathrm{D}}$ ratio increases nearly linearly in the range of $0.24-0.75$ from single to eight layers of graphene [60]. Analysis of the Raman spectra in the light spots showed that they are only composed of 1-8 layers of graphene whereas the dark spots present a highly oriented pyrolytic graphite (HOPG).

The same assay was performed for the samples of the silvered por-Si (Figure 2b). One can see that the silvered por-Si provides twice the increase of the Raman signal due to the SERS-activity. To find a number of the graphene layers we made a quantitative analysis of the Raman and SERS spectra (see Table S1). The graphene monolayer can be found on both substrates. This follows from the position of the $G$ band $\left(1587 \mathrm{~cm}^{-1}\right)$, the full width at half maximum (FWHM) of the $2 \mathrm{D}$ band $\left(29 \mathrm{~cm}^{-1}\right)$ and the $\mathrm{I}_{\mathrm{G}} / \mathrm{I}_{2 \mathrm{D}}$ ratio. The band associated with deformation, disorder, and defects in crystalline structure of graphene $\left(\sim 1350 \mathrm{~cm}^{-1}\right)$ cannot be found in the spectra evidencing its good quality [59].

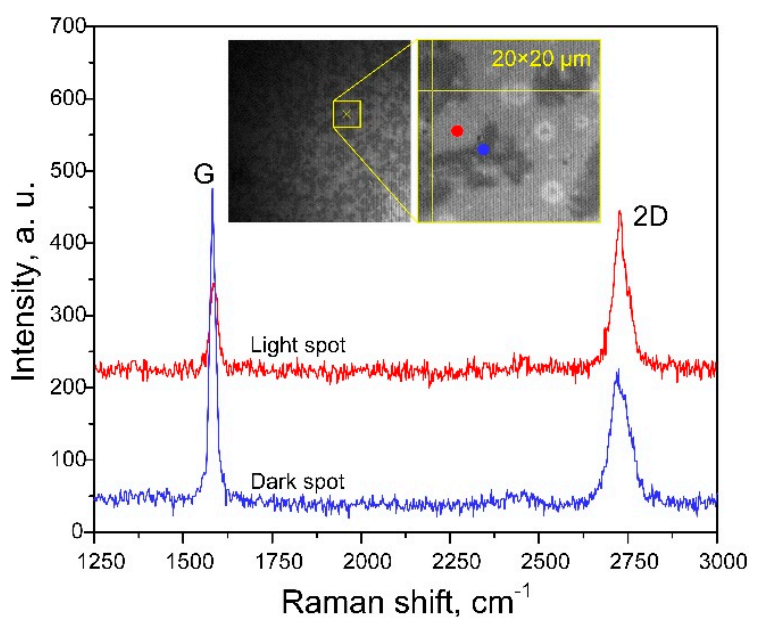

(a)

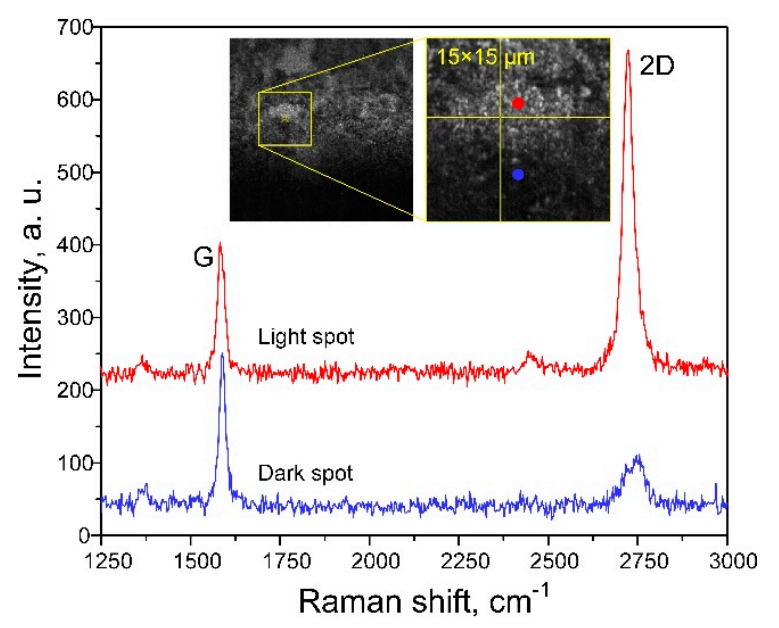

(b)

Figure 2. (a) Raman and (b) SERS spectra of graphene-containing film on the (a) $c$-Si and (b) silvered por-Si substrates registered in the light and dark spots. Insets show the Rayleigh images of the graphene-containing film.

\subsection{SERS-Activity of the Silvered por-Si Covered with Graphene}

In this section, we experimentally studied the effect of graphene on the SERS-spectra of the test analyte R6G. First, the SERS-spectrum of the analyte on the silvered por-Si was measured. Next, the sample with analyte was covered with graphene-containing film and the SERS-spectra in the light and dark points were registered. Schematic representations of the SERS-active substrates are shown on Figure 3. Figure 4 demonstrates that the morphology of the SERS-active substrates was not significantly changed after coating with graphene. 


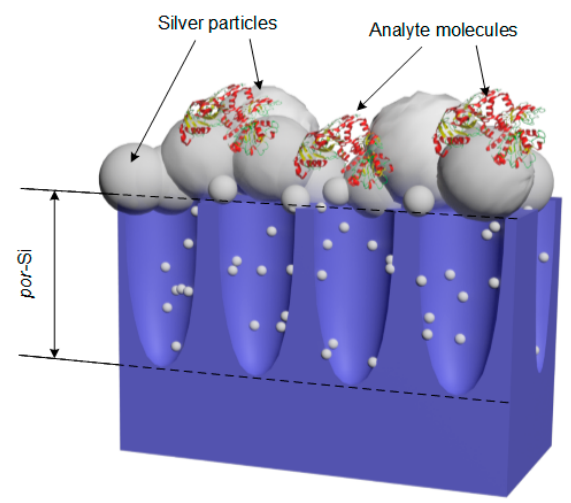

(a)

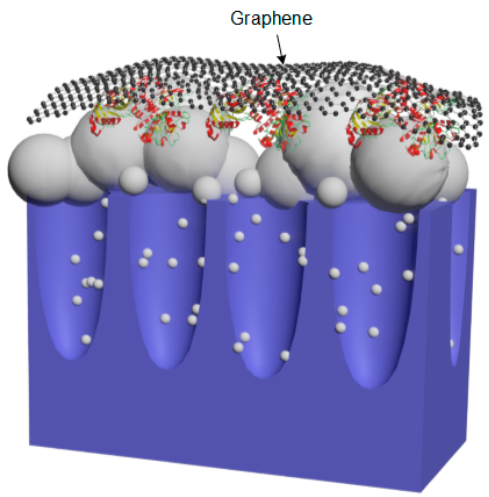

(b)

Figure 3. Schematic views of the SERS-active substrates: (a) The silvered por-Si with adsorbed analyte molecules; (b) the silvered por-Si with adsorbed analyte molecules coated with graphene.

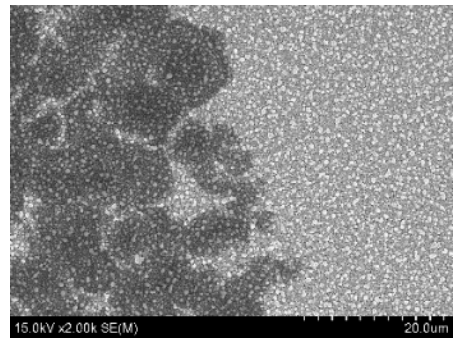

(a)

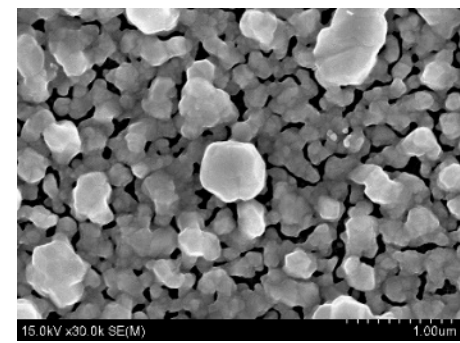

(b)

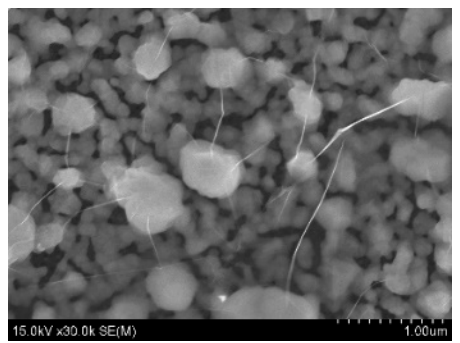

(c)

Figure 4. SEM top view images of the silvered por-Si: (a) Interface between graphene-covered and graphene-free areas at low magnification; (b) graphene-free surface; (c) graphene-covered surface.

Figure 5 shows SERS spectra of the R6G molecules adsorbed on the silvered por-Si free of graphene and covered with it. Each spectrum was measured at the laser power reduced by one order of magnitude. Laser exposition was 2 s. A deviation of the SERS intensity did not exceed 7\% for all the samples. It can be seen that the intensity of the SERS spectrum of R6G adsorbed on the silvered por-Si under the graphene-containing film in the light spot is 2-2.5 times more than that for the analyte molecules, which are not protected with the carbon nanostructure. At the same time, the SERS intensity of the analyte spectrum in the dark spot under graphene is significantly weaker than that of the substrate free of graphene. The R6G bands at 1310,1510, and $1574 \mathrm{~cm}^{-1}$ are suppressed in the SERS-spectrum registered on the graphene-free substrate and partially overlapped by the bands associated with amorphous carbon (1339 and $1597 \mathrm{~cm}^{-1}$ ) [61], i.e., the analyte burned during the measurements whereas the graphene protection eliminated this effect. Therefore, the film containing 1-8 graphene layers provides an additional enhancement of the SERS signal and prevents analyte destruction. Contrariwise, the HOPG spots inhibit the SERS-activity but also protects the analyte from the burning. 


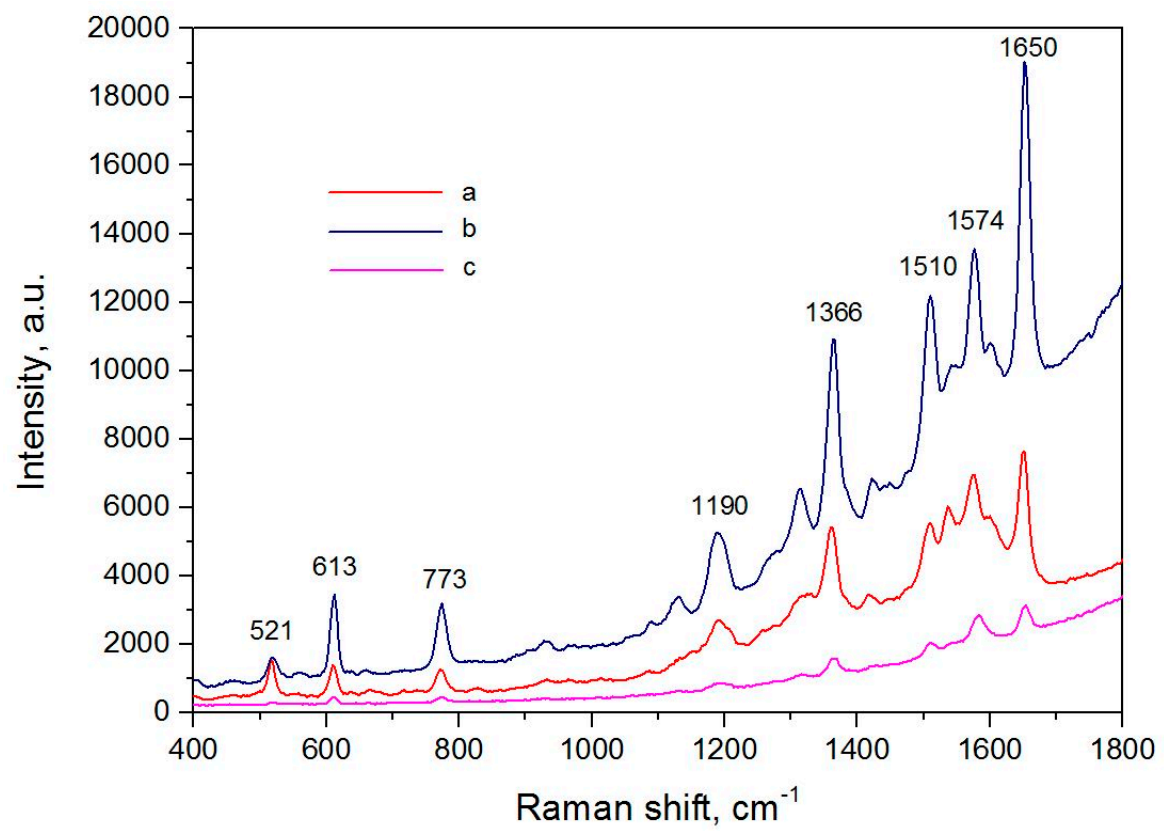

Figure 5. SERS-spectra of R6G molecules adsorbed from $10^{-6} \mathrm{M}$ solution on the silvered por-Si: (a) Free of graphene; (b) covered with graphene, in the light spot; (c) covered with graphene, in the dark spot.

\subsection{Simulation of the Silvered por-Si Covered with Graphene}

A better understanding of the graphene effect on the SERS measurements requires computer simulations of an electric field and a temperature distribution in the silvered por-Si free of graphene and covered with it. Silver hemispheres with a diameter of $80 \mathrm{~nm}$ (an average size of the silver particles in the real structure estimated from the SEM images) were placed on a thick substrate at a distance between their centers of $85 \mathrm{~nm}$. Refractive index of the substrate was chosen to correspond with that of an amorphous silicon. We used thermal properties of a slightly oxidized mesoporous silicon (thermal conductivity $34 \mathrm{~W} /(\mathrm{m} \cdot \mathrm{K})$ ) for the substrate in heat transfer calculations. The graphene layer was optically and thermally thin (three monolayers) with a $2500 \mathrm{~W} /(\mathrm{m} \cdot \mathrm{K})$ thermal conductivity.

The laser heating of the structure was simulated in two steps. First, we solved a 2D frequency-domain wave equation for the electric field with a finite element method in order to obtain the electromagnetic losses from the electromagnetic waves as a heat source. To simulate the excitation laser light, we used a Gaussian electromagnetic wave in the scattered-field formulation. The beam propagated in the negative y-direction. The wavelength was $473 \mathrm{~nm}$ and the spot radius of the tightly focused beam was $305 \mathrm{~nm}$. The incident power of the beam was $1 \mathrm{~mW}$. Next, we solved a heat transfer in a solids stationary equation to see the equilibrium temperature distribution in our structure with the graphene layer and free of it.

The graphene-containing film was found to have no effect on the electric field strength between the silver particles, which is maximal in the center of the laser spot. The electric field distribution around the silver hemispheres typical for both graphene-free and graphene-covered substrates is presented in Figure S4. Simulations revealed that the maximum temperature is about 10 degrees lower in the graphene-covered structure ( $341 \mathrm{~K}$ vs. $350 \mathrm{~K}$ ) (Figure S5a,b). Isothermal contours also showed a better heat propagation in a lateral direction in this structure (Figure S5c,d). The value of $350 \mathrm{~K}$ is very close to the point of lactoferrin denaturation [62] and laser heating can destruct protein's molecules, especially at trace amounts. A decrease of the temperature provided by covering the SERS-active substrate with graphene provides the opportunity for the protection of the lactoferrin molecules from partial denaturation. 


\subsection{SERS-Spectroscopy of Lactoferrin Molecules}

The initial SERS-measurement of lactoferrin was devoted to reveal if the silvered por-Si substrate provides the registration of its spectrum free of changes caused by the interaction of the bioorganic molecule with metallic particles and denaturation under laser irradiation. We suppose that lactoferrin is adsorbed nearly uniformly by the surface of the silvered por-Si because its isoelectric point is 8.3 while the measured $\mathrm{pH}$ of lactoferrin solutions at all concentrations was 6.5-7. Upon these conditions, the lactoferrin molecules are positively charged and attracted by the negatively charged silver surface. We measured the surface potential of the silvered por-Si during immersion into the water solution of lactoferrin and found that it increased from -0.3 to $-0.2 \mathrm{~V}$ for $2 \mathrm{~min}$. After that, the surface potential periodically deviated around the latter value by $\pm 0.04 \mathrm{~V}$. We suppose this deviation is connected with the surface charge changes. It shows that positive lactoferrin molecules are attracted and adsorbed by the negative metallic surface and as the potential increases, they are repulsed and slightly desorbed into the solution.

Figure 6 shows the SERS spectra of the silvered por-Si and the lactoferrin molecules adsorbed on this substrate from $10^{-6} \mathrm{M}$ solution. We aligned the spectra according to the position of the Si band at $521 \mathrm{~cm}^{-1}$. The SERS spectra were registered during $1 \mathrm{~s}$ at laser power $1.45 \mathrm{~mW}$. The substrate's spectrum has just bands signifying the $c-\mathrm{Si}\left(521 \mathrm{~cm}^{-1}\right)$ and $\mathrm{SiO}_{2}\left(978 \mathrm{~cm}^{-1}\right)$ contents. There is no evidence that silver oxide is in the sample, which proves the results described in Section 3.1. The SERS spectrum of lactoferrin is characterized by the presence of all bands typical for this analyte such as $1005 \mathrm{~cm}^{-1}$ (Phe), 1230-1300 $\mathrm{cm}^{-1}$ (Amide III and/or Tyr), 1340 and $1360 \mathrm{~cm}^{-1}$ (Trp), $1447 \mathrm{~cm}^{-1}$ $\left(\delta \mathrm{CH}_{2}\right.$ ), 1547 and $1560 \mathrm{~cm}^{-1}$ (Trp), $1600-1615 \mathrm{~cm}^{-1}$ (Tyr) and $1665 \mathrm{~cm}^{-1}$ (Amide I) [11,63]. To show the similarity of the SERS spectra of lactoferrin, its Raman spectrum registered for the $10^{-4} \mathrm{M}$ solution on the silicon can be found in Figure S6. A correlation of intensities of the bands in 1260-1290 $\mathrm{cm}^{-1}$ shows the hydrophobicity of the molecular environment of Trp residues. The bands between 1547 and $1560 \mathrm{~cm}^{-1}$ show the orientation in the Trp indole ring in relation to the peptide backbone, doublet signifies about two different orientations. Considering the Amide I band, we needed to analyze its position which can vary from 1620 to $1700 \mathrm{~cm}^{-1}$. In our case, it was at $1665 \mathrm{~cm}^{-1}$ and corresponds to the $\beta$-sheet content. It is known that lactoferrin contains both alpha helices and beta structure $[62,64]$. In [62] the authors estimated the percentage of alpha helices and beta strands from the Raman spectra during temperature changes. Heating the lactoferrin molecules caused a prevalence of residues in the beta structure but its percentage was found not to reach $100 \%$. In our work, the heating effect from the laser can lead to a more prominent Amide I band, which position is typical for the beta structure. Thus, the less intensive Amide I band related to alpha helices will be overlapped with that of the beta strands. Here, it is very likely caused by the thermal effect from the laser. The other marker of the secondary structure is the Amide III band located between 1230 and $1300 \mathrm{~cm}^{-1}$ but here it can be hidden in rather intensive Tyr bands $\left(1260-1290 \mathrm{~cm}^{-1}\right)$.

Next, we revealed the minimal concentration of the lactoferrin solution at which its molecules are still detected after adsorption on the silvered por-Si. Figure 7 presents the SERS spectra of lactoferrin at $10^{-6}$ to $10^{-18} \mathrm{M}$ concentrations, which were obtained by the collection and integration of the SERS spectra maps. We used two SERS-active substrates from different batches and scanned a $10 \times 10$ $\mu \mathrm{m}$ surface area of both substrates with a step of $1 \mu \mathrm{m}$. Each point of the maps was excited for $2 \mathrm{~s}$. The laser power was decreased to $0.14 \mathrm{~mW}$ in contrast to the previous measurement to eliminate a harmful photothermal effect. 


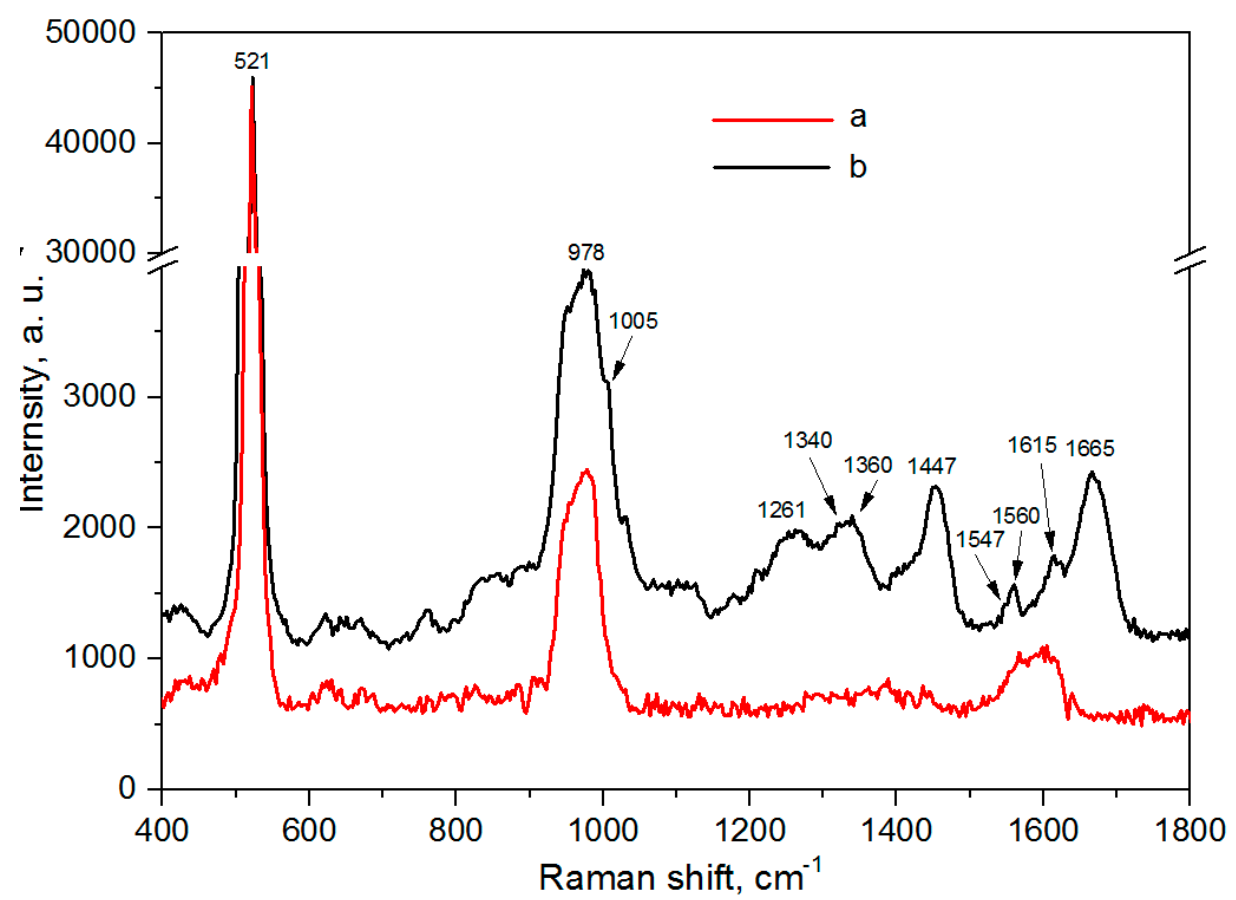

Figure 6. SERS spectra of the silvered por-Si: (a) Virgin; (b) after adsorption of the lactoferrin molecules from the $10^{-6} \mathrm{M}$ solution.

The SERS spectrum of lactoferrin adsorbed from $10^{-6} \mathrm{M}$ is rather weak but the decrease of the concentration down to $10^{-12} \mathrm{M}$ led to the enormous growth of the SERS signal. Lactoferrin mostly exists in tetramer and monomer forms $[65,66]$. Supposedly, tetramers are at concentrations higher than $10^{-10} \mathrm{M}$ while the lower amount of this analyte leads it to turning into a monomer form. Tetramers are too large for the uniform interaction with the electromagnetic field from the silver particles to provide an intensive SERS signal from the top part of the molecules. At the same time, monomers can lay between the metallic structures and be completely excited. The SERS spectra at the $10^{-14}$ and $10^{-16} \mathrm{M}$ concentrations have lower intensities and at $10^{-18} \mathrm{M}$ the pattern typical for amorphous carbon is observed.

All the informative SERS spectra are characterized by the presence of this analyte bands. Some burning of the analyte with the concentration decrease is observed as bands related to the amorphous carbon (around 1339 and $1597 \mathrm{~cm}^{-1}$ ) become broader. We still observe bands at 1002-1005 $\mathrm{cm}^{-1}$ (Phe ring breathing mode), $1130 \mathrm{~cm}^{-1}$ (corresponding to C-N bonds), 1350 and $1380-1390 \mathrm{~cm}^{-1}$ (Trp residues), $1450 \mathrm{~cm}^{-1}\left(\delta \mathrm{CH}_{2}\right), 1610-1615 \mathrm{~cm}^{-1}$ (Tyr) and $1647-1650 \mathrm{~cm}^{-1}$ (Amide I). The bands at $859 \mathrm{~cm}^{-1}$ (the asymmetric C-C-S stretching of Met side) and at $1170 \mathrm{~cm}^{-1}$ (the CO bending of the phenolate ligand) are now prominent in contrast to the previous single measurement due to a better enhancement and spectra integration. We also see intensive Tyr bands at $1257-1260$ and $1290 \mathrm{~cm}^{-1}$. Alternatively, one of these bands can be Amide III and signify the domination of the $\alpha$-helical structure, which is also proved by the position of the Amide I band. In this case, the Amide I band related to the beta strands is hidden in more intensive bands of alpha helices. Therefore, the signature of only $\beta$-sheet structure in the spectrum registered for the higher laser power could be caused by overheating. Unfortunately, the bands at 1547 and $1560 \mathrm{~cm}^{-1}$ can be overlapped by the wide band of amorphous carbon with maxima at $1576 \mathrm{~cm}^{-1}$. However, the spectra analysis gives an idea that this doublet coalesced in one band shifted to $1560 \mathrm{~cm}^{-1}$ because no hint of any band at $1547 \mathrm{~cm}^{-1}$ can be found. If so, this can confirm that the prevalent orientation of the indole ring is at an intermediate angle.

For the deeper understanding of the adsorption of the lactoferrin molecules on the SERS-active surface they were studied by SEM and EDX after immersion to the lactoferrin solutions at different concentrations. It was revealed that at the $10^{-6} \mathrm{M}$ and $10^{-8} \mathrm{M}$ concentrations the surface of the 
samples was randomly covered by separate accumulations of nanoparticles with diameters varying from a couple to hundred nanometers (Figure 8a,b). The number of accumulations was about 10 per $1200 \mu \mathrm{m}^{2}$ for both concentrations. However, an average area taken by the single accumulation was different: the average area of one accumulation is nearly $15 \mu \mathrm{m}^{2}$ for the $10^{-6} \mathrm{M}$ concentration and is $\sim 7.5 \mu \mathrm{m}^{2}$ for the $10^{-8} \mathrm{M}$ concentration. Thus, the number of nanoparticles decreased with a lowering concentration. EDX analysis showed that the atomic percentage of carbon in these accumulations is more than that on the surface free of the accumulations (Figure 8c,d). Supposedly, these accumulations can be a result of the lactoferrin precipitation when its molecules are adsorbed on the SERS-active substrates. SEM views of the samples related to $10^{-10} \mathrm{M}$ and less are not presented as they showed no difference with those free of lactoferrin. However, we were able to register the lactoferrin's SERS spectra, i.e., its molecules were adsorbed on the substrate. Smaller nanoparticles containing the lactoferrin molecules are not observed on the SEM pictures but this can be caused by limitations in resolution. The volume of the lactoferrin monomer is $0.132 \mathrm{~nm}^{3}$ [67] and we can estimate its average diameter of $\sim 0.65 \mathrm{~nm}$. Considering the SEM resolution of $1 \mathrm{~nm}$, it can be assumed that lactoferrin is adsorbed as monomer at concentrations lower than $10^{-10} \mathrm{M}$. To reveal the character of the lactoferrin molecules distribution we registered the SERS maps of the $10 \times 10 \mu \mathrm{m}$ area with a $500 \mathrm{~nm}$ step. The maps of the SERS intensity of the main protein bands were created. Two of them (according to the intensity of 1005 and $1290 \mathrm{~cm}^{-1}$ bands) for $10^{-6}$ and $10^{-12} \mathrm{M}$ concentrations are presented in Figure 9. The sample with lactoferrin at the micromolar concentration was studied in the area of its molecules' accumulation, which was found at the Rayleigh's mode. The intensive SERS signal was not observed in the thick layer of accumulation as the electromagnetic field from the metallic particles is not able to excite them. In contrast, it was registered in the particular spots close to the accumulation, where the lactoferrin molecules in a lower amount were adsorbed. The case of picomolar concentration shows more points of the SERS-spectra of lactoferrin. The above-described results show that the lactoferrin molecules were adsorbed on the SERS-active substrate non-uniformly. The lactoferrin solutions with concentrations higher than $10^{-10} \mathrm{M}$ led to the accumulation of the lactoferrin molecules in the nanoparticles (precipitations) with diameters of a couple to a hundred nanometers. The use of the more diluted solutions resulted in the accumulations size smaller than two nanometers or no accumulations at all.

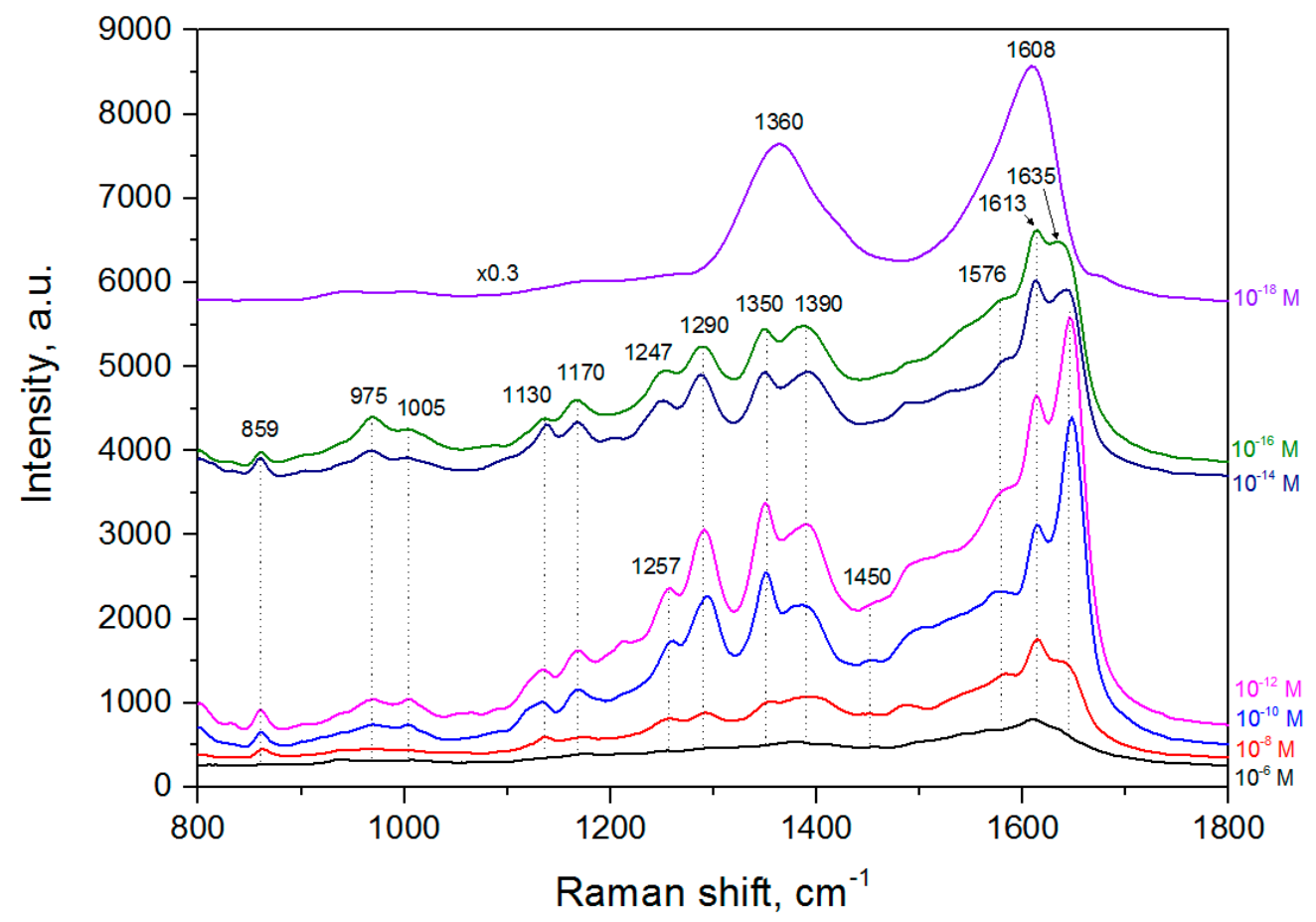

Figure 7. SERS spectra of the lactoferrin molecules adsorbed on the silvered por-Si. 
We were able to analyze the lactroferrin molecules adsorbed on the silvered por-Si down to the $10^{-16} \mathrm{M}$ concentration. However, at the $10^{-18} \mathrm{M}$ concentration we found just the bands corresponded to the amorphous carbon. We suppose that the $10^{-16} \mathrm{M}$ concentration is still enough to provide adsorption a plenty of molecules at several close to each other silver particles, which are in the laser spot. This allows getting the enhanced signal from a number of molecules located around the central point in the laser spot that is the most heated. Lower concentration leads to less amount of the adsorbed molecules, which cannot provide getting of proper enhancement within the laser spot, while burned species result in the high interference from vibration of amorphous carbon bonds.

Usually an analyte concentration during the SERS measurements is estimated using a comparison of intensities of the selected bands reflected in a calibration curve. As a rule, the intensity of the signal decreases with the concentration lowering. This dependence results in a linear calibration curve. The data obtained in our work do not have an ordinary view, i.e., the SERS signal intensity of the analyte is not directly correlated with its concentration. This is caused by the specificity of adsorption and the distribution of the lactoferrin molecules and their structural form at different concentrations. Therefore, the calibration curves have a non-linear character. The intensities of the bands at 1005 and $1290 \mathrm{~cm}^{-1}$ were used (Figure 10) to find calibration curves that visualize the dependence of the SERS intensity on the lactoferrin concentration. The values of the SERS intensities for some concentrations overlapped, if the single band was selected. For instance, the SERS intensities of the $1005 \mathrm{~cm}^{-1} \mathrm{band}$ were, very close in the pairs at the $10^{-6} \mathrm{M} / 10^{-12} \mathrm{M}$ and $10^{-14} \mathrm{M} / 10^{-16} \mathrm{M}$ concentrations. However, for the $1290 \mathrm{~cm}^{-1}$ band the other pairs were characterized by similar SERS intensities (the $10^{-6}$ $\mathrm{M} / 10^{-14} \mathrm{M}$ and $10^{-8} \mathrm{M} / 10^{-12} \mathrm{M}$ concentrations). Therefore, to objectively estimate the lactoferrin concentration it is recommended to measure the SERS intensities of two or even more bands.

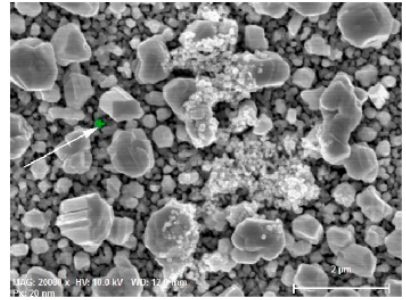

(a)

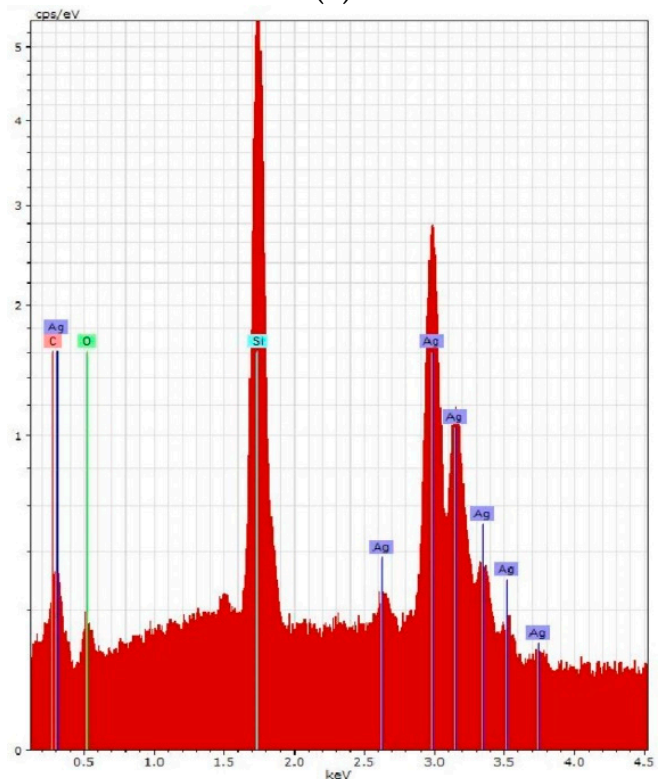

(c)

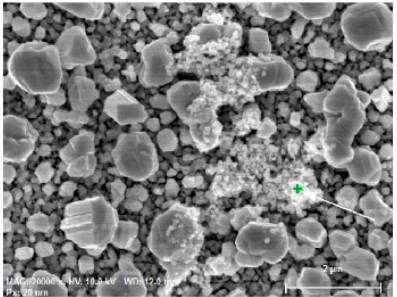

(b)

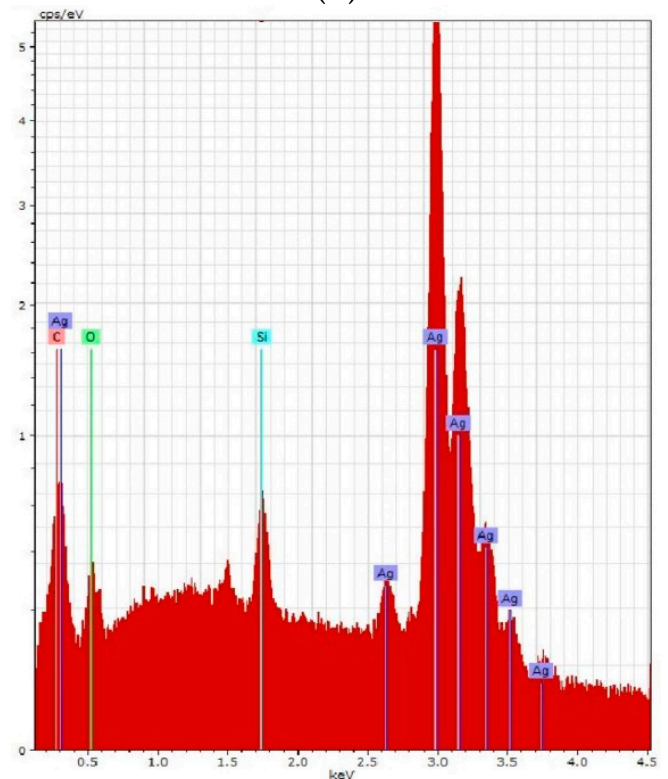

(d)

Figure 8. (a,b) SEM top view images of the silvered por-Si after adsorption of the lactoferrin molecules; (c,d) EDX spectra corresponded to the spots marked with a green cross on the SEM images. 

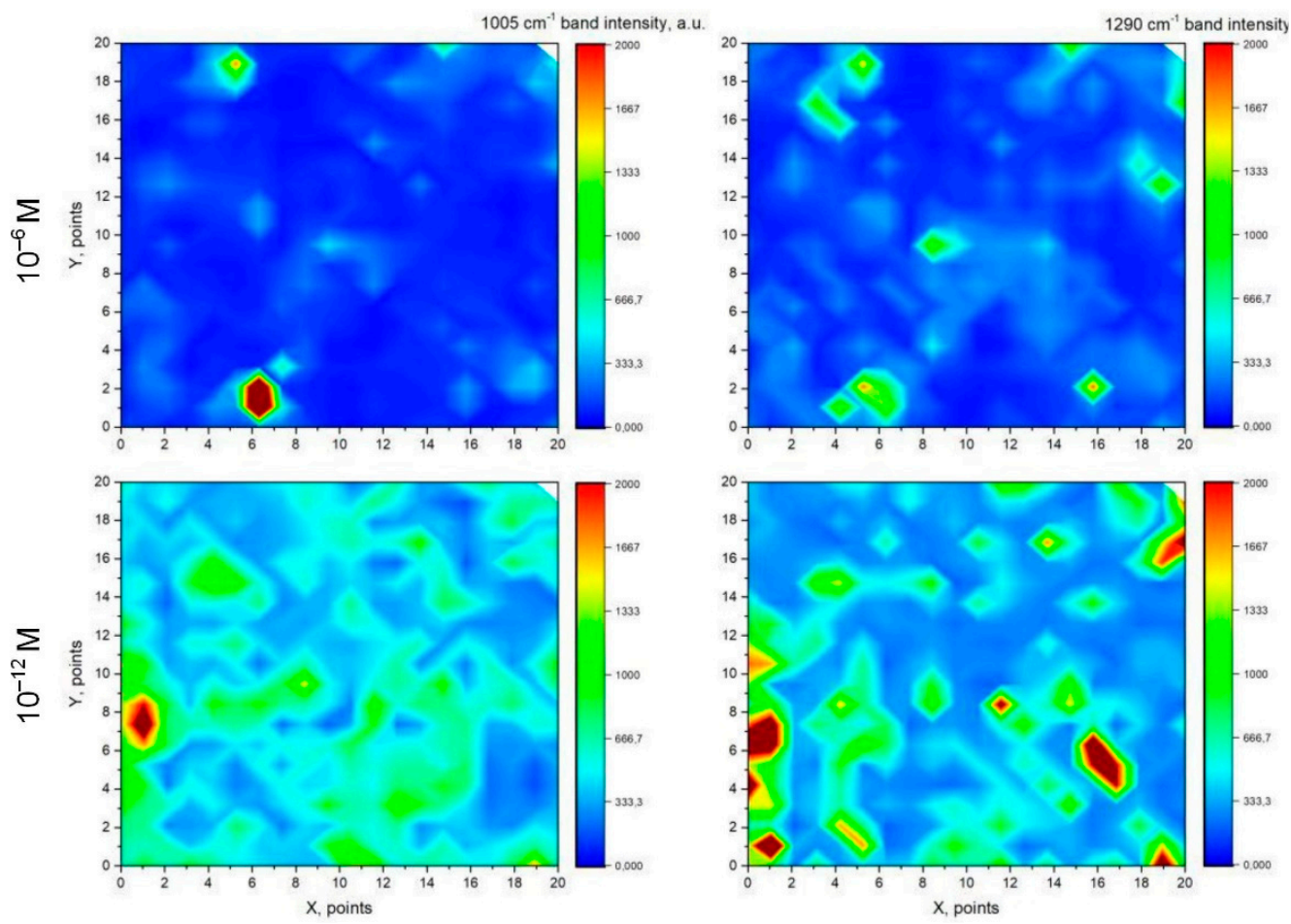

Figure 9. Distribution of the SERS-signal intensity at the 1005 and $1290 \mathrm{~cm}^{-1}$ bands in the SERS-spectra of the lactoferrin molecules adsorbed on the silvered por-Si from the solutions at $10^{-6}$ and $10^{-12} \mathrm{M}$. The size of each map is $10 \times 10 \mu \mathrm{m}$.

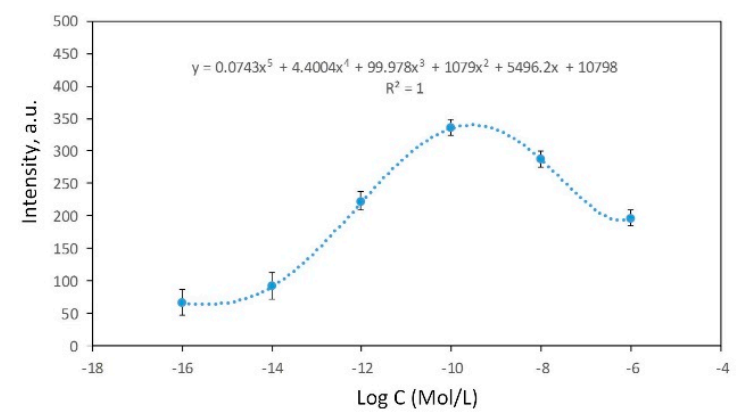

(a)

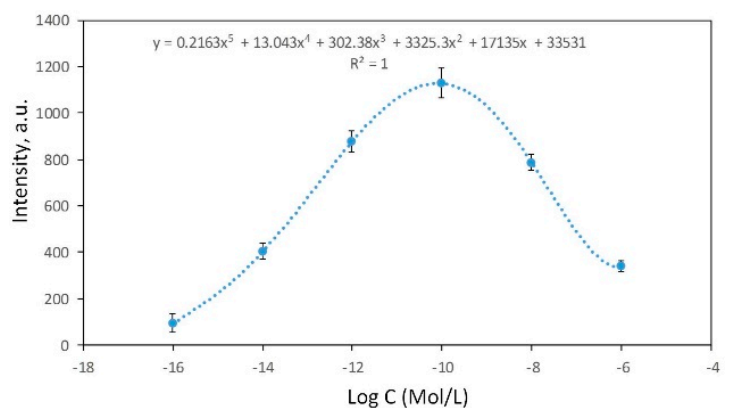

(b)

Figure 10. The calibration curves of the SERS intensities at the (a) 1005 and (b) $1290 \mathrm{~cm}^{-1}$ bands vs. the lactoferrin concentration. The curves were calculated using a polynomial fitting of the fifth order.

To overcome the limitation of the $10^{-16} \mathrm{M}$ lactoferrin concentration, at which it can be detected, we used the protection with graphene that was tested on the R6G molecules in the Section 3.3. In our experiments, we used the volume of $1 \mathrm{~mL}$ of the lactoferrin solutions. In case of the $10^{-18} \mathrm{M}$ concentration, there are $10^{-21}$ moles of the protein molecules. Multiplication of this amount by Avogadro's constant will give 602 lactoferrin molecules. The SERS-active area was $0.25 \mathrm{~cm}^{2}$ $\left(=25 \times 10^{6} \mu \mathrm{m}^{2}\right)$ so there are $25 \times 10^{4}$ square maps of $100 \mu \mathrm{m}^{2}$ area on it. Even if all the molecules are adsorbed on the SERS-active surface, the probability to catch one lactoferrin molecule in one map is negligibly small and can be calculated as $602 /\left(25 \times 10^{4}\right) \approx 0.24 \%$. That is why we recorded several maps before the lactoferrin spectrum was found. It should be noted that the maps were chosen from the light areas of the sample surface, which contain 1-8 graphene layers. Figure 11 shows the SERS spectrum obtained for the lactoferrin molecules adsorbed from the solution of attomolar concentration on the silvered por-Si and then coated with graphene. We registered spectrum during $2 \mathrm{~s}$. Despite the SERS spectrum intensity being relatively low, most of the lactoferrin Raman bands were presented 
there: $1002 \mathrm{~cm}^{-1}$ (Phe), $1290 \mathrm{~cm}^{-1}$ (Amide III), $1340 \mathrm{~cm}^{-1}$ (Trp), $1440 \mathrm{~cm}^{-1}\left(\delta \mathrm{CH}_{2}\right), 1605 \mathrm{~cm}^{-1}$ (Tyr) and $1642 \mathrm{~cm}^{-1}$ (Amide I).

Therefore, if the graphene-free substrates result in non-informative SERS spectra this can signify that the analyte concentration is lower than $10^{-16} \mathrm{M}$. To check the presence of the lactoferrin molecules the SERS-active substrate should be covered with the graphene-containing layer after immersion in the water solution. If the SERS mapping reveals the lactoferrin spectra, the concentration of the analyte will be $10^{-18} \mathrm{M}$.

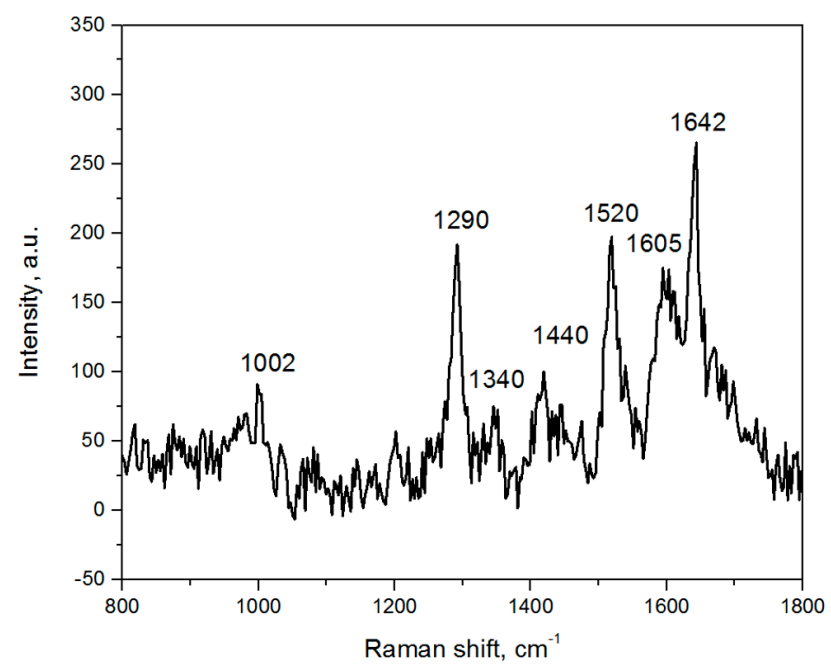

Figure 11. SERS spectrum of the lactoferrin molecules adsorbed on the silvered por-Si from $10^{-18} \mathrm{M}$ solution and then protected with graphene.

Considering the non-uniform distribution of the lactoferrin molecules that have a tendency to get together on the substrates, it is reasonable to assume that a laser could hit the spot of several or even more molecules.

\section{Conclusions}

In the present work, we overcame the hurdles of the SERS-spectroscopy to study the biomolecules with high molecular weight using the lactoferrin as test analyte. To achieve the objectives of the work, the SERS-active substrates based on the silvered por-Si and the graphene protection of the analyte molecules were applied. We were able to measure the SERS spectra of the human lactoferrin molecules adsorbed on the silvered por-Si from the $10^{-6}-10^{-18} \mathrm{M}$ water solutions. It was found that the por-Si causes a negative surface potential of silver particles and their chemical resistivity to oxidation in contrast to those deposited on the $c$-Si surface. It must be caused by an extremely developed surface of the por-Si template enriched with silicon broken bonds. These features promoted the attraction of the positively charged lactoferrin molecules and prevented their interaction with metallic particles upon $473 \mathrm{~nm}$ laser excitation, which typically is not used to study proteins. The SERS spectra of lactoferrin adsorbed from $10^{-6} \mathrm{M}$ solution were rather weak but the decrease of the concentration down to the $10^{-10} \mathrm{M}$ level led to the enormous growth of the SERS signal. This effect was observed because at the $10^{-6}-10^{-8} \mathrm{M}$ concentrations protein molecules coalesced in accumulations of its nanoparticles that are too large for the uniform interaction with the electromagnetic field from the silver particles to provide an intensive SERS signal from the molecules. Lower concentrations led to the adsorption of much smaller particles (equal to monomers in size) that can be completely excited. Considering the tendency of lactoferrin oligomers breaking to the monomers while its concentration in solution decreases [59], this result can be used to reveal the structural form of lactoferrin. The SERS-spectra at the $10^{-14}$ and $10^{-16} \mathrm{M}$ concentrations were less intensive and started to change (more prominent amorphous carbon bands) due to heating to the temperature of lactoferrin denaturation at about $350 \mathrm{~K}$. To decrease the 
temperature in the laser spot to $340 \mathrm{~K}$, the analyte molecules on the silvered por-Si were protected with graphene, which allowed detecting lactoferrin adsorbed from the $10^{-18} \mathrm{M}$ solution. All the registered SERS spectra of lactoferrin contained most of the vibrational bands typical for this analyte. Therefore, the SERS-active substrates based on the silvered por-Si can be used for the label-free study of the correlation of vibrational wavenumbers of protein and to find lactoferrin in its water solutions at the concentrations down to attomolar. It should be mentioned that according to our knowledge a reliable SERS study of the lactoferrin molecules adsorbed on the solid SERS-active substrates has not been reported before. However, we have not yet estimated the lactoferrin concentration in any mixture of proteins or in the biological fluids. This research is now undergoing to apply the SERS-spectroscopy with the substrates based on the silvered por-Si both free and protected with graphene to detect lactoferrin in complex proteins' solutions and physiological fluids.

Supplementary Materials: The following are available online at http:/ / www.mdpi.com/2079-6374/9/1/34/s1: Figure S1: Original views of the SERS-active substrates: The samples of the silicon wafer with the square $0.5 \times 0.5 \mathrm{~cm}$ area of the silvered por-Si placed in the Eppendorf tubes. Figure S2: SEM images of the silvered por-Si: (a) Top view; (b) cross-section, Figure S3: EDX spectrum typical for the silvered Si-based substrate, Figure S4: Electric field strength distribution simulated for the silvered por-Si: (a) Overview; (b) in the laser spot, Figure S5: $(a, b)$ Temperature distributions and $(c, d)$ isothermal contours simulated for the silvered por-Si: $(a, c)$ free of graphene; $(b, d)$ covered with graphene, Figure S6: Raman spectrum of lactoferrin $\left(10^{-4} \mathrm{M}\right.$ water solution). Table S1: Parameters of the Raman and SERS-spectra of the graphene-containing films.

Author Contributions: Conceptualization, H.B. and V.L.; methodology, K.G., I.K., I.S. and S.R.; software, S.Z., S.R.; validation, S.Z., N.K. (Nikolai Kovalchuk) and H.B.; formal analysis, S.Z. and S.R.; investigation, S.Z., N.K. (Nadia Khinevich), I.S., V.L., K.M. and M.V.; resources, I.K., V.L., G.A. and H.B.; data curation, S.Z., S.R. and M.V.; writing-original draft preparation, H.B.; writing-review and editing, H.B., G.A. and V.L.; visualization, S.Z. N.K. (Nikolai Kovalchuk), S.R. and H.B.; supervision, H.B.; project administration, H.B.; funding acquisition, H.B.

Funding: This research was funded in part by the Belarusian State Program of Scientific Research ("Photonics, opto- and microelectronics", task number 1.4.01) and the Belarusian Foundation of Fundamental Research (grant number $\Phi 18 \mathrm{P}-236)$.

Acknowledgments: The authors would like to thank V. Bondarenko (Belarusian State University of Informatics and Radioelectronics), V.V. Khrustalev for the fruitful discussions related to this publication and the Moscow office of COMSOL for access to the software.

Conflicts of Interest: The authors declare no conflict of interest.

\section{References}

1. Arduini, F.; Cinti, S.; Scognamiglio, V.; Moscone, D.; Palleschi, G. How cutting-edge technologies impact the design of electrochemical (bio) sensors for environmental analysis. A review. Anal. Chim. Acta 2017, 959, 15-42. [CrossRef] [PubMed]

2. De Lépinay, L.M.; Pigeau, B.; Besga, B.; Vincent, P.; Poncharal, P.; Arcizet, O. A universal and ultrasensitive vectorial nanomechanical sensor for imaging 2D force fields. Nat. Nanotechnol. 2016, 12, 156-162. [CrossRef] [PubMed]

3. Merker, J.D.; Oxnard, G.R.; Compton, C.; Diehn, M.; Hurley, P.; Lazar, A.J.; Turner, N.C. Circulating Tumor DNA Analysis in Patients with Cancer: American Society of Clinical Oncology and College of American Pathologists Joint Review. Arch. Pathol. Lab. Med. 2018, 36, 1631-1641. [CrossRef]

4. Nie, S.; Shi, T.; Fillmore, T.L.; Schepmoes, A.A.; Brewer, H.; Gao, Y.; Liu, T. Deep-Dive Targeted Quantification for Ultrasensitive Analysis of Proteins in Nondepleted Human Blood Plasma/Serum and Tissues. Anal. Chem. 2017, 89, 9139-9146. [CrossRef] [PubMed]

5. Chen, K.; Yuen, C.; Aniweh, Y.; Preiser, P.; Liu, Q. Towards ultrasensitive malaria diagnosis using surface enhanced Raman spectroscopy. Sci. Rep. 2016, 6. [CrossRef] [PubMed]

6. Newman, A.M.; Bratman, S.V.; To, J.; Wynne, J.F.; Eclov, N.C.W.; Modlin, L.A.; Diehn, M. An ultrasensitive method for quantitating circulating tumor DNA with broad patient coverage. Nat. Med. 2014, 20, 548-554. [CrossRef] [PubMed]

7. Cardoso, A.R.; Moreira, F.T.C.; Fernandes, R.; Sales, M.G.F. Novel and simple electrochemical biosensor monitoring attomolar levels of miRNA-155 in breast cancer. Biosens. Bioelectron. 2016, 80, 621-630. [CrossRef] [PubMed] 
8. Kelly, J.W. The two shapes of the Tau protein. Alzheimer's Dis. 2018, 7, e38516. [CrossRef] [PubMed]

9. Kushibiki, T.; Tu, Y.; Abu-Yousif, A.O.; Hasan, T. Photodynamic activation as a molecular switch to promote osteoblast cell differentiation via AP-1 activation. Sci. Rep. 2015, 5, 13114. [CrossRef] [PubMed]

10. Tretzel, L.; Görgens, C.; Geyer, H.; Thomas, A.; Dib, J.; Guddat, S.; Thevis, M. Analyses of Meldonium (Mildronate) from Blood, Dried Blood Spots (DBS), and Urine Suggest Drug Incorporation into Erythrocytes. Int. J. Sports Med. 2016, 37, 500-502. [CrossRef] [PubMed]

11. Rygula, A.; Majzner, K.; Marzec, K.M.; Kaczor, A.; Pilarczyk, M.; Baranska, M. Raman spectroscopy of proteins: A review. J. Raman Spectrosc. 2013, 44, 1061-1076. [CrossRef]

12. Natan, M.J. Concluding Remarks: Surface enhanced Raman scattering. Faraday Discuss. 2016, 132, $321-328$. [CrossRef]

13. Sharma, H.S.S.; Carmichael, E.; McCall, D. Fabrication of SERS substrate for the detection of rhodamine 6G, glyphosate, melamine and salicylic acid. Vib. Spectrosc. 2016, 83, 159-169. [CrossRef]

14. Kneipp, K.; Wang, Y.; Kneipp, H.; Perelman, L.T.; Itzkan, I.; Dasari, R.R.; Feld, M.S. Single Molecule Detection Using Surface-Enhanced Raman Scattering (SERS). Phys. Rev. Lett. 1997, 78, 1667-1670. [CrossRef]

15. Pomastowski, P.; Sprynskyy, M.; Žuvela, P.; Rafińska, K.; Milanowski, M.; Liu, J.J.; Buszewski, B. Silver-Lactoferrin Nanocomplexes as a Potent Antimicrobial Agent. J. Am. Chem. Soc. 2016, 138, 7899-7909. [CrossRef] [PubMed]

16. Metz-Boutique, M.H.; Jolles, J.; Mazurier, J.; Schoentgen, F.; Legrand, D.; Spik, G.; Montreuil, J.; Jolles, P. Human lactotransferrin: Amino acid sequence and structural comparisons with other transferrins. Eur. J. Biochem. 1984, 145, 659-676. [CrossRef]

17. Kanwar, J.R.; Roy, K.; Patel, Y.; Zhou, S.F.; Singh, M.R. Multifunctional iron bound lactoferrin and nanomedicinal approaches to enhance its bioactive functions. Molecules 2015, 20, 9703-9731. [CrossRef] [PubMed]

18. Johansson, B. Isolation of an iron-containing red protein from human milk. Acta Chem. Scand. 1960, 14, 510-512. [CrossRef]

19. Birgens, H. Lactoferrin in plasma measured by an ELISA technique: Evidence that plasma lactoferrin is an indicator of neutrophil turnover and bone marrow activity in acute leukaemia. Scand. J. Haematol. 1985, 34, 326-331. [CrossRef] [PubMed]

20. Jensen, O.L.; Gluud, B.S.; Birgens, H.S. The concentration of lactoferrin in tears of normals and of diabetics. Acta Ophthalmol. 1986, 64, 83-87. [CrossRef]

21. Ohashi, Y.; Ishida, R.; Kojima, T.; Goto, E.; Matsumoto, Y.; Watanabe, K.; Tsubota, K. Abnormal protein profiles in tears with dry eye syndrome. Am. J. Ophthalmol. 2003, 136, 291-299. [CrossRef]

22. Buccigrossi, V.; de Marco, G.; Bruzzese, E.; Ombrato, L.; Bracale, I.; Polito, G.; Guarino, A. Lactoferrin Induces Concentration-Dependent Functional Modulation of Intestinal Proliferation and Differentiation. Pediatr. Res. 2007, 61, 410-414. [CrossRef] [PubMed]

23. Filik, J.; Stone, N. Drop coating deposition Raman spectroscopy of protein mixtures. Analyst 2007, 132, 544-550. [CrossRef] [PubMed]

24. Zalutski, I.V.; Lukianova, N.Y.; Storchai, D.M.; Burlaka, A.P.; Shvets, Y.V.; Borikun, T.V.; Todor, I.M.; Lukashevich, V.S.; Rudnichenko, Y.A.; Chekhun, V.F. Influence of exogenous lactoferrin on the oxidant/antioxidant balance and molecular profile of hormone receptor-positive and -negative human breast cancer cells in vitro. Exp. Oncol. 2017, 39, 106-111. [CrossRef]

25. Lukashevich, V.S.; Budzevich, A.I.; Semak, I.V.; Kuznetsova, V.N.; Malyushkova, E.V.; Pyzh, A.E.; Novakovskaya, S.A.; Rudnichenko, J.A.; Popkov, N.A.; Ivashkevich, O.A.; et al. Production of recombinant human lactoferrin from the milk of goat-producers and its physiological effects. Dokl. Natl. Acad. Sci. Belarus 2016, 60, 72-81.

26. Lai, S.; Wang, S.; Luo, J.; Lee, L.J.; Yang, S.-T.; Madou, M.J. Design of a compact disk-like microfluidic platform for enzyme-linked immunosorbent assay. Anal. Chem. 2004, 76, 1832-1837. [CrossRef] [PubMed]

27. Satija, J.; Punjabi, N.; Mishra, D.; Mukherji, S. Plasmonic-ELISA: Expanding horizons. RSC Adv. 2016, 6, 85440-85456. [CrossRef]

28. Pan, Y.; Sonn, G.A.; Sin, M.L.Y.; Mach, K.E.; Shih, M.-C.; Gau, V.; Wong, P.K.; Liao, J.C. Electrochemical immunosensor detection of urinary lactoferrin in clinical samples for urinary tract infection diagnosis. Biosens. Bioelectron. 2010, 26, 649-654. [CrossRef] [PubMed] 
29. Zitka, O.; Krizkova, S.; Skalickova, S.; Dospivova, D.; Adam, V.; Kizek, R. Microfluidic tool coupled with electrochemical assay for detection of lactoferrin isolated by antibody-modified paramagnetic beads. Electrophoresis 2013, 34, 2120-2128. [CrossRef] [PubMed]

30. Yin, Z.; Fei, L.; Wei, W.; Xin, D.; Jia, R.; Qiuguang, S. Determination of Bovine Lactoferrin in Food by HPLC with a Heparin Affinity Column for Sample Preparation. J. AOAC Int. 2017, 100, 133-138. [CrossRef]

31. Król, J.; Litwińczuk, Z.; Brodziak, A.; Barłowska, J. Lactoferrin, lysozyme and immunoglobulin G content in milk of four breeds of cows managed under intensive production system. Pol. J. Vet. Sci. 2010, 13, 357-361. [PubMed]

32. Lee, S.; Kumar, P.; Hu, Y.; Cheng, G.J.; Irudayaraj, J. Graphene laminated gold bipyramids as sensitive detection platforms for antibiotic molecules. Chem. Commun. 2015, 51, 15494-15497. [CrossRef] [PubMed]

33. Koglin, E.; Séquaris, J.M.; Fritz, J.C.; Valenta, P. Surface enhanced Raman scattering (SERS) of nucleic acid bases adsorbed on silver colloids. J. Mol. Struct. 1984, 114, 219-223. [CrossRef]

34. Bantz, K.C.; Meyer, A.F.; Wittenberg, N.J.; Im, H.; Kurtuluş, Ö.; Lee, S.H.; Haynes, C.L. Recent progress in SERS biosensing. Phys. Chem. Chem. Phys. 2011, 13, 11551. [CrossRef] [PubMed]

35. Cialla, D.; März, A.; Böhme, R.; Theil, F.; Weber, K.; Schmitt, M.; Popp, J. Surface-enhanced Raman spectroscopy (SERS): Progress and trends. Anal. Bioanal. Chem. 2011, 403, 27-54. [CrossRef] [PubMed]

36. Miclăuş, T.; Beer, C.; Chevallier, J.; Scavenius, C.; Bochenkov, V.E.; Enghild, J.J.; Sutherland, D.S. Dynamic protein coronas revealed as a modulator of silver nanoparticle sulphidation in vitro. Nat. Commun. 2016, 7, 11770. [CrossRef] [PubMed]

37. Chan, S.; Kwon, S.; Koo, T.W.; Lee, L.P.; Berlin, A.A. Surface-Enhanced Raman Scattering of Small Molecules from Silver-Coated Silicon Nanopores. Adv. Mater. 2003, 15, 1595-1598. [CrossRef]

38. Lin, H.; Mock, J.; Smith, D.; Gao, T.; Sailor, M.J. Surface-Enhanced Raman Scattering from Silver-Plated Porous Silicon. J. Phys. Chem. B 2004, 108, 11654-11659. [CrossRef]

39. Giorgis, F.; Destrovi, E.; Chiodoni, A.; Froner, E.; Scarpa, M.; Venturello, A.; Geobaldo, F. Porous silicon as efficient surface enhanced Raman scattering (SERS) substrate. Appl. Surf. Sci. 2008, 254, 7494-7497. [CrossRef]

40. Terekhov, S.N.; Panarin, A.Y.; Kholostov, K.I.; Bondarenko, V.P.; Turpin, P.Y. Nanostructured silver films on meso- and macroporous silicon layers as a substrate for surface-enhanced Raman scattering. Phys. Chem. Appl. Nanostruct. 2009, 507-510. [CrossRef]

41. Kosović, M.; Balarin, M.; Ivanda, M.; Đerek, V.; Marciuš, M.; Ristić, M.; Gamulin, O. Porous Silicon Covered with Silver Nanoparticles as Surface-Enhanced Raman Scattering (SERS) Substrate for Ultra-Low Concentration Detection. Appl. Spectrosc. 2015, 69, 1417-1424. [CrossRef] [PubMed]

42. Hakonen, A.; Rindzevicius, T.; Schmidt, M.S.; Andersson, P.O.; Juhlin, L.; Svedendahl, M.; Käll, M. Detection of nerve gases using surface-enhanced Raman scattering substrates with high droplet adhesion. Nanoscale 2016, 8, 1305-1308. [CrossRef] [PubMed]

43. Arzumanyan, G.; Doroshkevich, N.; Mamatkulov, K.; Shashkov, S.; Girel, K.; Bandarenka, H.; Borisenko, V. Phospholipid detection by surface-enhanced Raman scattering using silvered porous silicon substrates. Phys. Status Solidi A 2017, 214, 1600915. [CrossRef]

44. Yakimchuk, D.; Kaniukov, E.; Bundyukova, V.; Osminkina, L.; Teichert, S.; Demyanov, S.; Sivakov, V. Silver nanostructures evolution in porous $\mathrm{SiO} 2 / \mathrm{p}$-Si matrices for wide wavelength surface-enhanced Raman scattering applications. MRS Commun. 2018, 8, 95-99. [CrossRef]

45. Bandarenka, H.; Artsemyeva, K.; Redko, S.; Panarin, A.; Terekhov, S.; Bondarenko, V. Effect of swirl-like resistivity striations in n+-type $\mathrm{Sb}$ doped $\mathrm{Si}$ wafers on the properties of $\mathrm{Ag}$ /porous silicon SERS substrates. Phys. Status Solidi C 2013, 10, 624-627. [CrossRef]

46. Wu, K.; Rindzevicius, T.; Schmidt, M.S.; Mogensen, K.B.; Hakonen, A.; Boisen, A. Wafer-scale leaning silver nanopillars for molecular detection at ultra-low concentrations. J. Phys. Chem. C 2015, 119, 2053-2062. [CrossRef]

47. Bandarenka, H.; Girel, K.; Zavatski, S.; Panarin, A.; Terekhov, S. Progress in the Development of SERS-Active Substrates Based on Metal-Coated Porous Silicon. Materials 2018, 11, 852. [CrossRef] [PubMed]

48. Cullis, A.G.; Canham, L.T.; Calcott, P.D.J. The structural and luminescence properties of porous silicon. J. Appl. Phys. 1997, 82, 909-965. [CrossRef]

49. Ling, X.; Xie, L.; Fang, Y.; Xu, H.; Zhang, H.; Kong, J.; Liu, Z. Can Graphene be used as a Substrate for Raman Enhancement? Nano Lett. 2010, 10, 553-561. [CrossRef] [PubMed] 
50. Lee, J.; Shim, S.; Kim, B.; Shin, H.S. Surface-Enhanced Raman Scattering of Single- and Few-Layer Graphene by the Deposition of Gold Nanoparticles. Chemistry 2011, 17, 2381-2387. [CrossRef] [PubMed]

51. Xu, W.; Mao, N.; Zhang, J. Graphene: A Platform for Surface-Enhanced Raman Spectroscopy. Small 2013, 9, 1206-1224. [CrossRef] [PubMed]

52. Dolgiy, A.; Redko, S.; Bandarenka, H.; Prischepa, S.; Yanushkevich, K.; Nenzi, P.; Bondarenko, V. Electrochemical Deposition and Characterization of Ni in Mesoporous Silicon. J. Electrochem. Soc. 2012, 159, D623-D627. [CrossRef]

53. Bandarenka, H.V.; Girel, K.V.; Bondarenko, V.P.; Khodasevich, I.A.; Panarin, A.Y.; Terekhov, S.N. Formation Regularities of Plasmonic Silver Nanostructures on Porous Silicon for Effective Surface-Enhanced Raman Scattering. Nanoscale Res. Lett. 2016, 11. [CrossRef] [PubMed]

54. Fransson, G.B.; Lonnerdal, B. Iron in human milk. J. Pediatr. 1980, 96, 380-384. [CrossRef]

55. Abe, H.; Saito, H.; Miyakawa, H.; Tayura, Y.; Shimamura, S.; Nagao, E.; Tomita, M. Heat Stability of Bovine Lactoferrin at Acidic pH. J. Dairy Sci. 1991, 74, 65-71. [CrossRef]

56. Bandarenka, H.; Shapel, A.; Balucani, M. Cu-Si Nanocomposites Based on Porous Silicon Matrix. Solid State Phenom. 2009, 151, 222-226. [CrossRef]

57. Girel, K.; Yantcevich, E.; Arzumanyan, G.; Doroshkevich, N.; Bandarenka, H. Detection of DNA molecules by SERS spectroscopy with silvered porous silicon as an active substrate. Phys. Status Solidi A 2016, 213, 2911-2915. [CrossRef]

58. Xiu, Z.; Zhang, Q.; Puppala, H.L.; Colvin, V.L.; Alvarez, P.J.J. Negligible Particle-Specific Antibacterial Activity of Silver Nanoparticles. Nano Lett. 2012, 12, 4271-4275. [CrossRef] [PubMed]

59. Calizo, I.; Balandin, A.A.; Bao, W.; Miao, F.; Lau, C.N. Temperature Dependence of the Raman Spectra of Graphene and Graphene Multilayers. Nano Lett. 2007, 7, 2645-2649. [CrossRef] [PubMed]

60. Das, A.; Chakraboty, B.; Sood, A. Raman spectroscopy of graphene on different substrates and influence of defects. Bull. Mater. Sci. 2008, 31, 579-584. [CrossRef]

61. Saito, R.; Hofmann, M.; Dresselhaus, G.; Jorio, A.; Dresselhaus, M.S. Raman spectroscopy of graphene and carbon nanotubes. Adv. Phys. 2011, 60, 413-550. [CrossRef]

62. Iafisco, M.; Foltran, I.; Di Foggia, M.; Bonora, S.; Roveri, N. Calorimetric and Raman investigation of cow's milk lactoferrin. J. Therm. Anal. Calorim. 2010, 103, 41-47. [CrossRef]

63. Khrustalev, V.V.; Khrustaleva, T.A.; Kahanouskaya, E.Y.; Rudnichenko, Y.A.; Bandarenka, H.V.; Arutyunyan, A.M.; Kordyukova, L.V. The alpha helix 1 from the first conserved region of HIV1 gp120 is reconstructed in the short NQ21 peptide. Arch. Biochem. Biophys. 2018, 638, 66-75. [CrossRef] [PubMed]

64. Gerstein, M.; Anderson, B.F.; Norris, G.E.; Baker, E.N.; Lesk, A.M.; Chothia, C. Domain Closure in Lactoferrin. J. Mol. Biol. 1993, 234, 357-372. [CrossRef] [PubMed]

65. Mantel, C.; Miyazawa, K.; Broxmeyer, H.E. Physical characteristics and polymerization during iron saturation of lactoferrin, a myelopoietic regulatory molecule with suppressor activity. Adv. Exp. Med. Biol. 1994, 357, 121-132. [PubMed]

66. Bagby, G.C.; Bennet, R.M. Feedback regulation of granulopoiesis: Polymerization of lactoferrin abrogates its ability to inhibit CSA production. Blood 1982, 60, 108-112. [PubMed]

67. Babina, S.E.; Tuzikov, F.V.; Tuzikova, N.A.; Buneva, V.N.; Nevinskii, G.A. Effect of nucleotides on the oligomeric state of human lactoferrin. Mol. Biol. 2006, 40, 121-131. [CrossRef]

(C) 2019 by the authors. Licensee MDPI, Basel, Switzerland. This article is an open access article distributed under the terms and conditions of the Creative Commons Attribution (CC BY) license (http://creativecommons.org/licenses/by/4.0/). 